\title{
Flumazenil Does Not Improve Hepatic Encephalopathy Associated with Acute Ischemic Liver Failure in the Rabbit
}

\author{
Carin C. D. van der Rijt, ${ }^{1}$ Robert J. de Knegt, ${ }^{1}$ Solko W. Schalm, ${ }^{1,2}$ \\ Onno T. Terpstra, ${ }^{1}$ and Karel Mechelse ${ }^{1}$
}

Received February 28, 1990; accepted May 15, 1990

\begin{abstract}
The effect of flumazenil, a benzodiazepine antagonist, on hepatic encephalopathy was studied in rabbits with acute hepatic failure induced by a two-stage liver devascularization procedure. The rabbits were randomized for treatment with $5 \mathrm{mg} / \mathrm{kg}$ of flumazenil or the placebo. The drug was administered at two easily recognizable time points in the course of the encephalopathy: first, when the righting reffex was disturbed, and second, when the animal could no longer achieve to the sitting position. The response after flumazenil did not differ from that after the placebo, as measured by clinical evaluation and automated EEG analysis. Furthermore, the progression of the encephalopathy, as measured by the survival time after the first injection, was not affected by flumazenil.
\end{abstract}

KEY WORDS: flumazenil; hepatic encephalopathy; acute hepatic failure; rabbits; experimental.

\section{INTRODUCTION}

Benzodiazepine receptor antagonists have been reported to improve hepatic encephalopathy (HE) in experimental (Baraldi et al., 1984; Bassett et al., 1987; Gammal et al., 1988; Zeneroli et al., 1988) as well as clinical (Scollo-Lavizzari et al., 1985; Bansky et al., 1985, 1989; Ferenci et al., 1989; Burke, 1988; Grimm et al., 1988) studies. The benzodiazepine receptor is part of the larger $\gamma$-aminobutyric acid (GABA)benzodiazepine receptor complex (Braestrup et al., 1983). It has been suggested that this receptor system may play a role in the pathogenesis of HE (Jones et al., 1984). Gamma-aminobutyric acid is the most important inhibitory neurotransmitter, accounting for $30-40 \%$ of the total neurotransmitter content in the brain (Walker,

\footnotetext{
${ }^{1}$ Department of Internal Medicine II, Laboratory for Experimental Surgery and Department of Electroneurology, Erasmus University, Rotterdam, The Netherlands.

${ }^{2}$ To whom correspondence should be addressed.
} 
1983). The binding of GABA to its receptor, and thus its inhibitory action on neuronal membranes, is enhanced by the binding of benzodiazepines to their own receptors (Braestrup et al., 1983). Benzodiazepine antagonists inhibit the binding of benzodiazepines but, on their own, are not believed to have an important intrinsic effect on central nervous system functioning (Braestrup et al., 1983). Therefore, apart from offering a new therapeutic approach to $\mathrm{HE}$, benzodiazepine antagonists may be important in studies on its pathogenesis: a beneficial effect may point to the presence of endogenous benzodiazepine-like compounds in $\mathrm{HE}$, as has been recently suggested (Basile et al., 1988).

Various compounds that antagonize the benzodiazepine receptor have been studied in animal models of acute hepatic failure: flumazenil, CGS 8216, and Ro154513. All ameliorated hepatic encephalopathy in rats and rabbits with galactosamine or thioacetamide-induced fulminant hepatic failure (Baraldi et al., 1984; Bassett et al., 1987; Gammal et al., 1988; Zeneroli et al., 1988). However, a beneficial effect of CGS 8216 could not be confirmed in rats with acute ischemic liver failure (Zieve et al., 1987). Furthermore, antagonism of the GABA receptor itself also did not affect the course of hepatic encephalopathy in this animal model (Rzepczynski et al., 1986). Therefore, further experimental controlled studies on the effect of a benzodiazepine antagonist in hepatic encephalopathy are needed. We studied the effect of flumazenil in our recently described rabbit model of acute ischemic liver failure (Fick et al., 1987). We measured the response by clinical evaluation of $\mathrm{HE}$, spectral analysis of the EEG, and determination of the survival time.

\section{MATERIALS AND METHODS}

Animals. Sixteen New Zealand white rabbits with acute ischemic liver failure were used. Four healthy control rabbits were studied to assess the intrinsic effect of flumazenil in comparison to that of diazepam.

Rabbits with Acute Hepatic Encephalopathy. Before surgery the rabbits received doxycycline, in dosages increasing to a maximum of $25 \mathrm{mg}$, in their drinking water for about 5 days. Food was withdrawn $24 \mathrm{hr}$ before surgery, except for glucose drinking water ad libitum. Anesthesia was induced with Hypnorm $(0.6-0.8 \mathrm{ml} \mathrm{im} ; 10 \mathrm{mg}$ of fluanison and $0.2 \mathrm{mg}$ of fentanyl base $/ \mathrm{ml}$ ). After intubation muscle relaxation was achieved with $1.0 \mathrm{mg}$ of Pavulon iv, and anesthesia was maintained with $\mathrm{N}_{2} \mathrm{O}: \mathrm{O}_{2}$ $(2: 1)$ and $0.025 \mathrm{mg}$ of fentanyl iv, whenever indicated. A Ringer-lactate solution $(20 \mathrm{ml} / \mathrm{hr})$ and Haemacel $(10 \mathrm{ml} / \mathrm{hr})$ were administered via a cannula in a marginal ear vein during the operation. To prevent acidosis, the infusion regimen was changed to $8.4 \%$ sodium bicarbonate at a rate of 15 and $30 \mathrm{ml} / \mathrm{hr}$ during and immediately after construction of the portacaval shunt (PCS), respectively. To monitor arterial blood pressure, blood gases, and $\mathrm{pH}$, a 5-Ch catheter was inserted in the right femoral artery. Fifty milligrams of amoxicilline was given as antibiotic prophylaxis.

The surgical procedure was performed as previously described (Fick et al., 1987). After severing the attachments of the liver, a small-diameter (5-mm) side-to-side PCS was constructed with 7-0 prolene within $15 \mathrm{~min}$. A loose ligature was placed around the hepatoduodenal ligament and threaded through a subcutaneous plastic tube. 
Three silver electrodes were placed directly on the dura mater through small burr holes in the skull. Two were implanted $5 \mathrm{~mm}$ to the right of the sagittal suture, $3 \mathrm{~mm}$ anterior and $11 \mathrm{~mm}$ posterior to the coronal suture, respectively, and the third was implanted $5 \mathrm{~mm}$ to the left of the sagittal suture and $3 \mathrm{~mm}$ anterior to the coronal suture.

Postoperatively the rabbits were given glucose water ad libitum, followed by a normal diet. The second day after surgery $50 \mathrm{mg}$ of amoxicilline was given iv and acute liver ischemia was induced by tightening the loose ligature around the hepatoduodenal ligament. To prevent hypoglycemia, an infusion of $10 \%$ glucose $(5 \mathrm{ml} / \mathrm{hr}$ ) was started, the dose being adjusted to maintain normoglycemia, which was controlled hourly. Body temperature was measured every $2 \mathrm{hr}$ and remained normal throughout the experiment. Before induction of liver ischemia and at regular intervals in the course of the experiment, spectral analysis was performed and arterial blood samples were taken. Every half-hour the rabbits were taken out of their restraining boxes for evaluation of the stage of $\mathrm{HE}$. Two easily recognizable clinical stages of $\mathrm{HE}$ could be identified in most animals. Stage A was characterized by a disturbed righting reflex: the animal not getting up immediately when placed on its side. At stage B the rabbit lay in the cage and could not come to the sitting position, not even after stimulation, and usually did not even lift its head. In some cases stage B was preceded by a period of agitation or marked ataxia. When stage A or B was identified the evaluation was repeated 10 min later for confirmation.

The rabbits were randomized for treatment with flumazenil or placebo. Flumazenil or the vehicle, $5 \mathrm{mg} / \mathrm{kg}$, was injected at a rate of $1 \mathrm{mg} / \mathrm{kg} / \mathrm{min}$. The effect of flumazenil on HE was evaluated clinically before and $10 \mathrm{~min}$ after the injection as well as by spectral analysis before and $5 \mathrm{~min}$ after the injection and by determination of the survival time after the first injection of flumazenil or placebo. Liver failure was confirmed by a rise in arterial ammonia levels and a decline in clotting factors. Autopsy studies of all rabbits were performed to verify that the hepatoduodenal ligament was adequately clamped.

Control Rabbits. Hypnorm, $0.5 \mathrm{ml} / \mathrm{kg}$, was administered intramuscularly and electrodes were placed on the dura mater, as described above. The effect of flumazenil was assessed in a randomized crossover study performed at least 1 week after the surgical procedure. For this purpose $5 \mathrm{mg} / \mathrm{kg}$ of flumazenil or the vehicle was injected at a rate of $1 \mathrm{mg} / \mathrm{kg} / \mathrm{min}$. After a washout period of 1 week the other compound was given. The effect was assessed by clinical evaluation of the animal before and $10 \mathrm{~min}$ after the injection and by spectral analysis before and 5 min after the injection. A similar crossover study was carried out to evaluate the effect of $5 \mathrm{mg} / \mathrm{kg}$ of diazepam versus that of $0.9 \%$ saline.

Spectral Analysis. The variations in potential between the electrodes over the right hemisphere were registered by an EEG apparatus (Ahrend-van Gogh, Amsterdam, The Netherlands) and fed into a computer at a sampling rate of $51.2 \mathrm{~Hz}$ and a sensitivity of 11 bits $/ 5 \mathrm{~V}$. A power spectrum was established, as described earlier (Van der Rijt et al., 1984). The frequency resolution was $0.1 \mathrm{~Hz}$. The mean dominant frequency (MDF), the power, and the percentages of the delta, theta, alpha, and betha frequency bands were calculated over the frequency range $1.0-25.6 \mathrm{~Hz}$.

Chemicals. Flumazenil was kindly provided by Hoffmann-La Roche \& Co, Mijdrecht, The Netherlands. Just before the experiment it was suspended in sterile 
distilled water at $37^{\circ} \mathrm{C}$ with Tween $80(1$ drop per $5 \mathrm{ml})$. Diazepam was solubilized in water with alcohol $(10 \%)$ and propylene glycol $(40 \%)$. Clotting factors were assessed by means of the Normotest (Nyegaard, Oslo, Norway). Arterial ammonia levels were measured by an enzymatic method using gluamate dehydrogenase.

Statistics. The Wilcoxon two-sample test was used for statistical comparisons. The effects on the MDF and survival times were analyzed with the paired or nonpaired Student $t$ test, whenever indicated; for analyzing the survival times logarithmic transformation was used.

\section{RESULTS}

Rabbits with Hepatic Encephalopathy. The degree of liver failure, as measured by the rise in arterial ammonia levels and the decline in Normotest values, in the group of rabbits treated with flumazenil was similar to that found for the placebo group (Fig. 1).

At stage A the effect of flumazenil or placebo could be studied in all 16 rabbits, although the time between the induction of liver ischemia and the diagnosis of this stage of $\mathrm{HE}$ varied considerably: $1.5-11.0 \mathrm{hr}$ for the flumazenil-treated and 1.5-10.5 hr for the placebo group. The righting reflex did not normalize in any of the rabbits after administration of either flumazenil or the placebo (Table I). Two rabbits treated with flumazenil and three rabbits receiving the placebo died before stage $B$ was identified or confirmed (most of them were agitated just before death). Therefore, at stage B
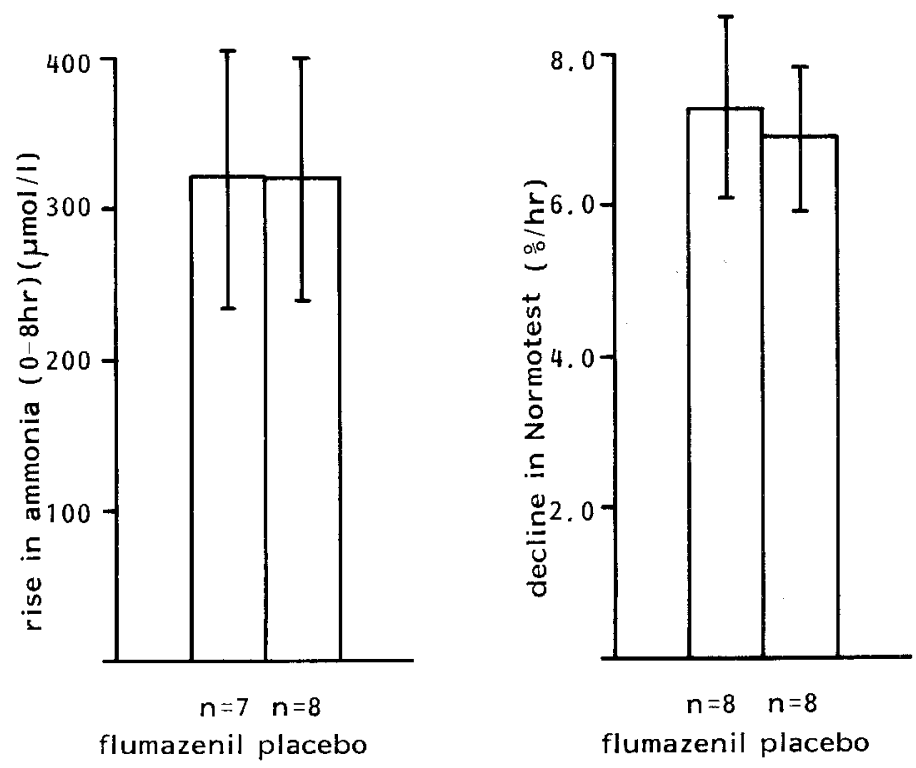

Fig. 1. Parameters of acute hepatic failure: on the left, the rise in arterial ammonia levels during the first $8 \mathrm{hr}$ after induction of liver ischemia; on the right, the hourly decrease in clotting factors, as assessed by Normotest. The results are expressed as mean $\pm \mathrm{SE}$. 

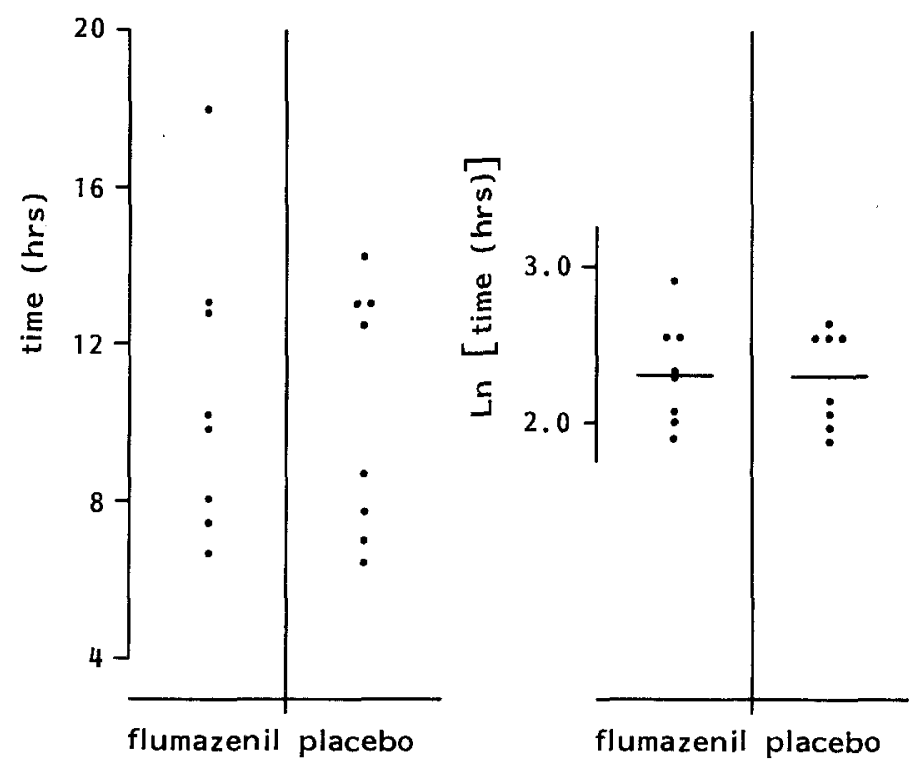

Fig. 2. Survival times after the first injection of flumazenil or the placebo: on the left, absolute values; on the right the same survival times after logarithmic transformation to obtain a normal distribution (-, mean).

Table I. Clinical Recovery After Flumazenil or Placebo

\begin{tabular}{lcc}
\hline & Flumazenil & Placebo \\
\hline Stage A & $0 / 8$ & $0 / 8$ \\
Stage B & $1 / 6$ & $1 / 5$ \\
\hline
\end{tabular}

six rabbits could be given flumazenil and five rabbits the placebo. In each group one animal died within $10 \mathrm{~min}$ of the injection and one animal regained the ability to sit (Table I).

The survival times after the first injection of either flumazenil or the placebo are shown in Fig. 2. Logarithmic transformation of the data was used to obtain a normal distribution. As the mean ratio of the survival times for the two groups after administration of the first injection was 1.04 (with a $95 \%$ confidence interval of 0.72 to 1.49 ), progression of $\mathrm{HE}$ was similar for flumazenil and the placebo.

The effects of flumazenil and placebo on the MDFs are shown in Table II and Fig. 3. At stage A the MDFs were already significantly decreased with respect to baseline values (paired Student's $t$ test). At this stage neither flumazenil nor the placebo induced normalization to the baseline values (Table II). At stage B the MDFs were decreased further, except in one animal with an MDF higher than the baseline value; in this animal a further increase occurred from 5.9 to $8.1 \mathrm{~Hz}$ after flumazenil, due to a peak in the power spectrum around $15 \mathrm{~Hz}$. A similar effect did not occur in other animals. At both stages of HE the changes in MDF with respect to the values before injection were calculated for each rabbit. The changes did not differ between flumazenil and placebo. At stage $A$ the mean difference between flumazenil and 


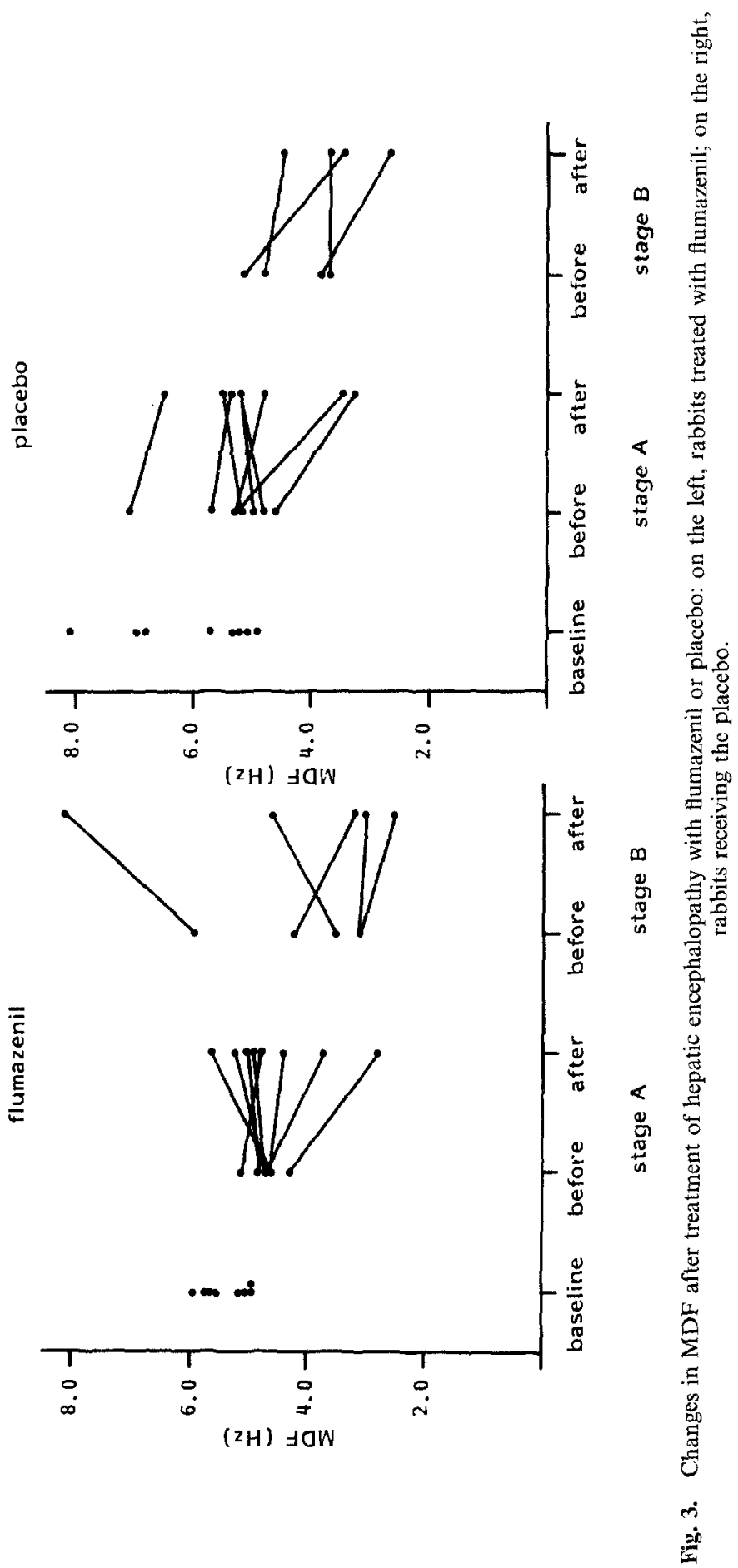


Table II. Changes in MDF (Hz) After Treatment of Hepatic Encephalopathy with Flumazenil or Placebo ${ }^{a}$

\begin{tabular}{|c|c|c|c|c|c|}
\hline & \multirow[b]{2}{*}{ Baseline } & \multicolumn{2}{|c|}{ Stage A } & \multicolumn{2}{|c|}{ Stage B } \\
\hline & & Before & After & Before & After \\
\hline Flumazenil & $5.33 \underset{(8)}{ \pm} 0.40$ & $4.69 \pm 0.22 *$ & $4.55 \frac{ \pm 0.90^{* *}}{(8)}$ & $4.20 \underset{(6)}{ \pm} 1.20$ & $4.28 \underset{(5)}{ \pm} 2.27$ \\
\hline Placebo & $6.00 \pm \frac{ \pm}{(8)} 1.14$ & $5.38 \underset{(8)}{ \pm} 0.77^{* * *}$ & $4.93 \pm 1.06^{*}$ & $4.92 \pm \frac{ \pm}{(5)} 1.41^{* *}$ & $3.60 \underset{(4)}{ \pm} 0.74^{* * *}$ \\
\hline
\end{tabular}

${ }^{a}$ Results are expressed as means $\pm \mathrm{SD}$, the number of rabbits is given in parentheses.

*Difference with respect to baseline, $P<0.01$.

**Difference with respect to baseline, $P<0.02$

***Difference with respect to baseline, $P<0.05$.

placebo was $0.31 \mathrm{~Hz}$ with a $95 \%$ confidence interval of -0.54 to $1.16 \mathrm{~Hz}$. At stage $B$ the mean difference was $1.07 \mathrm{~Hz}$, with a $95 \%$ confidence interval of -0.68 to $2.82 \mathrm{~Hz}$. There were also no differences in the effects on power and the delta, theta, alpha, and beta percentages of the power spectrum after the first as well as the second injection.

Control Rabbits. The effects of flumazenil and the placebo were studied in four rabbits, and the effects of diazepam and physiologic saline in three rabbits. After flumazenil behavioral changes did not occur and spectral analysis showed only minimal changes (Table III). A similar dose of diazepam induced marked lethargy: the animals could be placed on their sides and they slept for the following hour. Electroencephalography revealed a high-amplitude rhythm with an increase in background delta activity. These changes were confirmed by the marked increase in power and percentage delta activity as measured by spectral analysis. The MDF, the percentage theta activity, and the percentage alpha activity decreased (Table III).

Table III. Changes in the Parameters of Spectral Analysis for Control Rabbits After Treatment with Flumazenil or Diazepam ${ }^{a}$

\begin{tabular}{|c|c|c|c|c|c|c|}
\hline \multirow{2}{*}{$\begin{array}{c}\text { Rabbit } \\
\text { No. }\end{array}$} & \multirow{2}{*}{$\begin{array}{c}\text { MDF } \\
(\mathrm{Hz})\end{array}$} & \multicolumn{5}{|c|}{ Percentage } \\
\hline & & Power & Delta & Theta & Alpha & Beta \\
\hline \multicolumn{7}{|c|}{ Flumazenil } \\
\hline 1 & +0.1 & +0.53 & -0.3 & -1.8 & +0.7 & +1.4 \\
\hline 2 & +0.5 & -43.67 & -3.9 & +0.5 & +0.8 & +2.6 \\
\hline 3 & +0.4 & -20.59 & -5.6 & +2.7 & -1.2 & +3.6 \\
\hline 4 & +0.5 & -13.41 & -6.0 & +2.0 & +2.2 & $\begin{array}{l}1.8 \\
+1.8\end{array}$ \\
\hline \multicolumn{7}{|l|}{ Diazepam } \\
\hline 1 & -1.7 & +484.62 & +25.3 & -17.3 & -5.8 & -2.2 \\
\hline 2 & -0.4 & +713.36 & +15.6 & -16.5 & -2.7 & +3.6 \\
\hline 3 & -0.5 & +612.85 & +8.4 & -5.7 & -4.4 & +1.5 \\
\hline
\end{tabular}

${ }^{a}$ Results are expressed as the changes with respect to the baseline values after diazepam or flumazenil minus these changes after the placebo; the change in power is expressed as the percentage change assuming that the power at baseline was $100 \%$. 


\section{DISCUSSION}

We could not demonstrate a beneficial effect of flumazenil on hepatic encephalopathy in our animal model of acute hepatic failure. Our findings are in accordance with the results from a rat model of acute ischemic liver failure (Zieve et al., 1987). An important role for an endogenous benzodiazepine-like compound in this animal model therefore seems unlikely. Our findings are contrary to the results of experimental controlled studies on benzodiazepine antagonists in galactosamine- and thioacetamideinduced acute liver failure (Baraldi et al., 1984; Bassett et al., 1987; Gammal et al., 1988; Zeneroli et al., 1988).

In the galactosamine animal models the effect of a benzodiazepine antagonist was investigated only during mild hepatic encephalopathy. All rats apparently regained normal clinical status (Baraldi et al., 1984) and neurological response scores improved in $75-100 \%$ of the rabbits (Bassett et al., 1987). Disturbed visual evoked responses normalized in both studies (Baraldi et al., 1984; Bassett et al., 1987). We could not demonstrate a clinical effect of flumazenil in any of the rabbits in stage A. The upper limit of the $95 \%$ confidence interval for this response in eight rabbits, $36.9 \%$, is therefore still much lower than the responses observed in the galactosamine models (Baraldi et al., 1984; Bassett et al., 1987). Furthermore, the MDF after flumazenil neither normalized to the baseline value nor showed an improvement significantly different from that in the animals receiving the placebo. Regarding the $95 \%$ confidence intervals for the difference in effect on the MDF between flumazenil and placebo $(-0.54$ to $1.16 \mathrm{~Hz}$ at stage $\mathrm{A}$ and -0.68 to $2.82 \mathrm{~Hz}$ at stage $\mathrm{B}$ ), a small effect of flumazenil cannot be excluded. Nevertheless, a discrepancy exists between the results in the galactosamine animal models (Baraldi et al., 1984; Bassett et al., 1987) and the results in our model of acute ischemic liver failure.

We used a highly reproducible rabbit model in which acute hepatic failure was induced by a two-stage liver devascularization procedure. Liver failure was confirmed by a decrease in clotting factors and a rise in arterial ammonia levels. All animals developed encephalopathy, as confirmed by the occurrence of two easily recognisable features of the encephalopathy: a disturbed righting reflex in all and loss of the ability to maintain posture. The survival of the animals after induction of liver ischemia was similar to that reported after total hepatectomy (Svedberg et al., 1983), which confirms the suitability of this animal model. Recently, the usefulness of an ischemic animal model for the study of hepatic encephalopathy has been questioned (Jones et al., 1987); however, scientific evidence is not available for this statement.

The concept of investigating the effect of a benzodiazepine antagonist on hepatic encephalopathy originated from studies on galactosamine-induced liver failure in rats and rabbits, in which increased numbers of brain GABA and benzodiazepine receptors were demonstrated using ligand-membrane binding essays (Baraldi et al., 1982, 1984; Schafer et al., 1983). Both flumazenil and CGS 8216 were found to have a beneficial effect in these animal models (Baraldi et al., 1984; Bassett et al., 1987) and antagonism of endogenous benzodiazepine-like compounds was suggested. However, later studies on the number of GABA and benzodiazepine receptors in different animal models of hepatic encephalopathy, including the rat model of acute ischemic liver failure, yielded no changes in GABA and benzodiazepine receptors (Thompson 
et al., 1985; Maddison et al., 1987a, b; Ferenci et al., 1987; Pappas et al., 1987; Roy et al., 1988). Furthermore, the finding of increased numbers of brain GABA and benzodiazepine receptors in the galactosamine rabbit model has recently been retracted (Rössle et al., 1989). Nevertheless, increased GABA-ergic tone is still postulated in this animal model (Rössle et al., 1989). A beneficial effect of a benzodiazepine antagonist on hepatic encephalopathy may be found only in an animal model in which the influence of the GABA-benzodiazepine receptor complex on central nervous system function is enhanced.

Another consideration seems worthwhile. Flumazenil may bind not only to central benzodiazepine receptors. A beneficial effect of flumazenil upon bloodpressure homeostasis was demonstrated in an animal model of hemorrhagic shock (Bitterman et al., 1987). A drop in blood pressure has been reported in galactosamineinduced liver failure (Grün et al., 1976; Brachtel et al., 1988) and may have contributed to the encephalopathy in this animal model of acute hepatic failure.

Differences in the types and doses of benzodiazepine antagonists might also explain the discordance between different studies. In the only published study on rabbits (with galactosamine-induced liver failure), a dose of $1-2.5 \mathrm{mg} / \mathrm{kg}$ of flumazenil was used to ameliorate hepatic encephalopathy (Bassett et al., 1987). We used a higher dose: $5 \mathrm{mg} / \mathrm{kg}$. This dose has been proven to antagonize marked benzodiazepine-induced slowing of the EEG in healthy rabbits, without causing any changes when given alone (Gogolák et al., 1985). To confirm the absence of an intrinsic benzodiazepine-like effect of flumazenil when given at this rather high dose, we compared the effects of a dose of $5 \mathrm{mg} / \mathrm{kg}$ of flumazenil and diazepam in healthy rabbits. Contrary to diazepam, flumazenil induced neither behavioral changes nor slowing of the electroencephalogram. Therefore, our negative findings cannot be explained easily by dose differences.

We studied the effect of flumazenil in both early and late hepatic encephalopathy. Since no effect of flumazenil could be detected in stage A, which occurred early in the course of the experiment, when brain edema was almost certainly absent, our negative findings cannot easily be explained by the presence of brain edema.

Flumazenil has been suggested to be of benefit in the treatment of hepatic encephalopathy in some uncontrolled clinical studies (Scollo-Lavizzari et al., 1985; Bansky et al., 1985, 1989; Ferenci et al., 1989; Burke, 1988; Grimm et al., 1988). However, negative results have now also been forthcoming (Sutherland et al., 1988; Klotz et al., 1989; Van der Rijt et al., 1989). Furthermore, GABA and benzodiazepine receptors were found to be unchanged in autopsied brain tissue from cirrhotic patients with hepatic encephalopathy (Butterworth et al., 1988). At present, no unequivocal evidence for an increased GABA-ergic tone is present in human hepatic encephalopathy. Our negative findings on the effect of flumazenil in our animal model of hepatic encephalopathy warrant further caution for its postulated benefit in clinical hepatic encephalopathy.

\section{ACKNOWLEDGMENTS}

The authors are grateful to Mr. P. Mulder for his statistical advice and the personnel of the laboratory of experimental surgery for their help in caring for the animals both before and during the operation. 


\section{REFERENCES}

Bansky, G., Meier, P. J., Ziegler, W. H., Walser, H., Schmid, M., and Huber, M. (1985). Reversal of hepatic coma by benzodiazepine antagonist Rol5-1788. Lancet 1: 1324-1325.

Bansky, G., Meier, P. J., Riederer, E., Walser, H., Ziegler, W. H., and Schmid, M. (1989). Effects of the benzodiazepine receptor antagonist flumazenil in hepatic encephalopathy in humans. Gastroenterology 97: 44-50.

Baraldi, M., and Zeneroli, M. L. (1982). Experimental hepatic encephalopathy: Changes in the binding of gamma-aminobutyric acid. Science 216: 427-429.

Baraldi, M., Zeneroli, M. L., Ventura, E., Penne, A., Pinelli, G., Ricci, P., and Santi, M. (1984). Supersensitivity of benzodiazepine receptors in hepatic encephalopathy due to fulminant hepatic failure in the rat: Reversal by a benzodiazepine antagonist. Clin. Sci. 67: 167-175.

Basile, A. S., and Gammal, S. J. (1988). Evidence for the involvement of the benzodiazepine receptor complex in hepatic encephalopathy. Implications for treatment with benzodiazepine receptor antagonists. Clin. Neuropharm. 11: 401-422.

Bassett, M. L., Mullen, K. D., Skolnick, P., and Jones, E. A. (1987). Amelioration of hepatic encephalopathy by pharmacologic antagonism of the GABA-A-benzodiazepine receptor complex in a rabbit model of fulminant hepatic failure. Gastroenterology 93: 1069-1077.

Bitterman, H., Lefer, D. J., and Lefer, A. M. (1987). Beneficial actions of Ro15-1788, a benzodiazepine receptor antagonist, in hemorrhagic shock. Meth. Find. Exp. Clin. Pharmacol. 9: 341-347.

Brachtel, D., and Wernze, H. (1988). Renin-angiotensin system, blood pressure homeostasis and renal function in galactosamine-induced fulminant hepatic failure in the guinea pig. Clin. Physiol. Biochem. 6: $95-105$.

Braestrup, C., Nielsen, M., Honoré, T., Jensen, L, H., and Petersen, E. N. (1983). Benzodiazepine ligands with positive and negative efficacy. Neuropharmacology 22: 1451-1457.

Burke, D. A. (1988). Reversal of hepatic coma with flumazenil with improvement in visual evoked potentials. Lancet 2: 505-506.

Butterworth, R. F., Lavoie, J., Giguère, J. F., and Pomier-Layrargues, G. (1988). Affinities and densities of high-affinity $\left[{ }^{3} \mathrm{H}\right]$ muscimol (GABA-A) binding sites and of central benzodiazepine receptors are unchanged in autopsied brain tissue from cirrhotic patients with hepatic encephalopathy. Hepatology 8: $1084-1088$.

Ferenci, P., Zieve, L., Ebner, J., Zimmermann, Ch., and Rzepczynski, D. (1987). Postsynaptic gammaaminobutyric acid receptors in hepatic coma following portacaval shunt and hepatic artery ligation in the rat. Metab. Brain Dis. 2: 195-200.

Ferenci, P., Grimm, G., Meryn, S., and Gangl, A. (1989). Successful long-term treatment of portalsystemic encephalopathy by the benzodiazepine antagonist flumazenil. Gastroenterology 96: 240-243.

Fick, T. E., Schalm, S. W., and De Vlieger, M. (1987). A surgical model of fulminant hepatic failure in the rabbit: Different effects of end-to-side versus small-diameter side-to-side portacaval shunt. Eur. Surg. Res. 19: 276-282.

Gammal, S. H., Jones, E. A., Bassett, M. L., Mullen, K. D., Geller, D., and Skolnick, P. (1988). Antagonists of the GABA/benzodiazepine receptor complex ameliorate hepatic encephalopathy in two models of fulminant hepatic failure. In Soeters, P. B., Wilson, J. H. P., Meijer, A. J., and Holm, E. (eds.), Advances in Ammonia Metabolism and Hepatic Encephalopathy, Proceedings of the 6th International Symposium on ammonia, Vaalsbroek Castle, The Netherlands, 27-29 April 1987, Elsevier, Amsterdam, pp. 325-332.

Gogolàk, G., Stumf, Ch., and Huck, S. (1985). Differentiation of drug-induced rhythmical activities in the rabbit's brain by a benzodiazepine antagonist. Arzneim-Forsch. 35: 233-236.

Grimm, G., Katzenschlager, R., Schneeweiss, B., Lenz, K., Ferenci, P., Madl, C., Laggner, A. N., and Gangl, A. (1988). Improvement of hepatic encephalopathy treated with flumazenil. Lancet 2: 13921394.

Grün, M., Liehr, H., and Rasenack, U. (1976). Significance of endotoxaemia in experimental "galactosamine-hepatitis" in the rat. Acta Hepato-Gastroenterol. 23: 64-81.

Jones, E. A., Schafer, D. F., Ferenci, P., and Pappas, S. C. (1984). The GABA hypothesis of the pathogenesis of hepatic encephalopathy: Current status. Yale J. Biol. Med. 57: 301-316.

Jones, E. A., Mullen, K. D., and Gammal, S. H. (1987). Hepatic encephalopathy. In Arias, I. M., Frenkel, M., and Wilson, J. H. P. (eds.), The Liver Annual 6, Elsevier, Amsterdam, pp. 396-415.

Klotz, U., and Walker, S. (1989). Flumazenil and hepatic encephalopathy. Lancet 1: 155-156.

Maddison, J. E., Dodd, P. R., Morrison, M., Johnston, G. A. R., and Farrell, G. C. (1987a). Plasma GABA, GABA-like activity and the brain GABA-benzodiazepine receptor complex in rats with chronic hepatic encephalopathy. Hepatology 7: 621-628. 
Maddison, J. E., Dodd, P. R., Johnston, A. R., and Farrell, G. C. (1987b). Brain gamma-aminobutyric acid receptor binding is normal in rats with thioacetamide-induced hepatic encephalopathy despite elevated plasma gamma-aminobutyric acid-like activity. Gastroenterology 93: 1062-1068.

Pappas, S. C., Levy, G., Gordon, V. P., Nakatsukasa, H., and Martin, P. (1988). The GABA hypothesis of hepatic encephalopathy: Further studies in multiple animal models. In Soeters, P. B., Wilson, J. H. P., Meijer, A. J., and Holm, E. (eds.), Advances in Ammonia Metabolism and Hepatic Encephalopathy, Proceedings of the 6th International Symposium on ammonia, Vaalsbroek Castle, The Netherlands, 27-29 April 1987, Elsevier, Amsterdam, pp. 259-264.

Rössle, M., Dẹckert, J., and Jones, E. A. (1989). Autoradiographic analysis of GABA-benzodiazepine receptors in an animal model of acute hepatic encephalopathy. Hepatology 10: 143-147.

Roy, S., Pomier-Layrargues, G., Butterworth, R. F., and Huet, P. M. (1988). Hepatic encephalopathy in cirrhotic and portacaval shunted dogs: lack of changes in brain GABA uptake, brain GABA levels, brain glutamic acid decarboxylase activity and brain postsynaptic GABA receptors. Hepatology 8: $845-849$.

Rzepczynski, D., Zieve, L., Lindblad, S., and LaFontaine, D. (1986). In vivo studies of GABAergic effects in experimental hepatic encephalopathy. Hepatology 6: 902-905.

Schafer, D. F., Fowler, J. M., Munson, P. J., Thakur, A. K., Waggoner, J. G., and Jones, E. A. (1983). Gamma-aminobutyric acid and benzodiazepine receptors in an animal model of fulminant hepatic failure. J. Lab. Clin. Med. 102: 870-880.

Scollo-Lavizzari, G., and Steinmann, E. (1985). Reversal of hepatic coma by benzodiazepine antagonist Ro15-1788. Lancet 1: 1324.

Sutherland, L. R., and Minuk, G. Y. (1988). Ro15-1788 and hepatic failure. Ann. Intern. Med. 108: 158.

Svedberg, A., Maddock, S., and Drury, D. D. (1938). The effect of total removal of the liver in the rabbit. Am. J. Physiol. 121: 209-214.

Thompson, J. S., Schafer, D. F., Schafer, G. J., and Hodgson, F. E. (1985). Gamma-aminobutyric acid plasma levels and brain binding in eck fistula dogs. J. Surg. Res. 38: 143-148.

Van der Rijt, C. C. D., Schalm, S. W., De Groot, G. H., and De Vlieger, M. (1984). Objective measurement of hepatic encephalopathy by means of automated EEG analysis. Electroenceph. Clin. Neurophysiol. 57: 423-426.

Van der Rijt, C. C. D., Schalm, S. W., Meulstee, J., and Stijnen, Th. (1989). Flumazenil therapy for hepatic encephalopathy: A double-blind cross-over study. Hepatology 10: 590 (abstract).

Walker, J. E. (1983). Glutamate, GABA and CNS disease: a review. Neurochem. Res. 8: 521-550.

Zeneroli, M. L., and Baraldi, M. (1988). Increased functional activity of the GABA-benzodiazepine receptor unit in a rat model of hepatic encephalopathy: Pharmacological evidence. Hepatology 8: 1388 (abstract).

Zieve, L., Ferenci, P., Rzepczynski, D., Ebner, J., and Zimmermann, C. (1987). A Benzodiazepine antagonist does not alter the course of experimental hepatic encephalopathy or neural gammaaminobutyric acid (GABA) binding. Metab. Brain Dis. 2: 201-205. 